\title{
$\dot{\nabla}_{\text {Nursing }}^{\text {Global Academic }}$
}

\section{Efeitos da ozonioterapia no tratamento de adiposidades: uma revisão integrativa}

\author{
Effects of ozone therapy on the treatment of adiposity: an integrative review
}

Efectos de la ozonoterapia en el tratamiento de la adiposidad: una revisión integradora

\author{
Isabelly Freitas Dias ${ }^{1}$ \\ ORCID: 0000-0001-9959-3907 \\ Sonia Regina Jurado ${ }^{1}$ \\ ORCID: 0000-0002-7220-4083 \\ ${ }^{1}$ Universidade Federal do Mato \\ Grosso do Sul. Mato Grosso do \\ Sul, Brasil.
}

\section{Como citar este artigo:}

Dias IF, Jurado SR. Efeitos da ozonioterapia no tratamento de adiposidades: uma revisão integrativa. Glob Acad Nurs. 2021;2(2):e144.

https://dx.doi.org/10.5935/26755602.20200144

\section{Autor correspondente:}

Sonia Regina Jurado

E-mail: srjmartins@yahoo.com.br

Editor Chefe: Caroliny dos Santos Guimarães da Fonseca Editor Executivo: Kátia dos Santos Armada de Oliveira

Submissão: 08-12-2021

Aprovação: 09-03-2021

\begin{abstract}
Resumo
Objetivou-se avaliar os efeitos da ozonioterapia no tratamento de adiposidades. Realizou-se uma revisão integrativa, durante o mês de outubro de 2020, nas bases de dados SciELO, LILACS, PubMed e Google Acadêmico, com os descritores: oxygen-ozone therapy, adiposity e os correspondentes em português e espanhol. Critérios de inclusão: artigos disponíveis na íntegra, nos idiomas português, inglês e espanhol e que continham pelo menos dois descritores no título ou resumo, publicados entre 2000 a 2020 . Foram selecionados cinco artigos científicos, um sobre obesidade, dois que versavam sobre lipomas e outros dois sobre gordura submentoniana (papada). O ozônio mostrou-se um ótimo agente lipolítico, reduzindo as adiposidades com poucas aplicações e sem efeitos colaterais. No entanto, mais estudos sobre ozonioterapia e tratamento de adiposidades são necessários para o estabelecimento das concentrações ideias e frequência de aplicação do ozônio a fim de garantir melhores resultados para o tratamento de disfunções estéticas, como gordura localizada e patologias, como lipomas.
\end{abstract}

Descritores: Ozônio; Célula Adiposa; Lipoma.

\section{Abstract}

The aim was to evaluate the effects of ozone therapy in the treatment of adiposity. An integrative review was carried out during the month of October 2020, in the SciELO, LILACS, PubMed and Academic Google databases, with the descriptors: oxygen-ozone therapy, adiposity and the corresponding ones in Portuguese and Spanish. Inclusion criteria: articles available in full, in Portuguese, English and Spanish and containing at least two descriptors in the title or abstract, published between 2000 and 2020. Five scientific articles were selected, one on obesity, two on lipomas and another two on submental fat (double chin). Ozone proved to be an excellent lipolytic agent, reducing adiposity with few applications and without side effects. However, more studies on ozone therapy and adiposity treatment are needed to establish the ideal concentrations and frequency of ozone application to guarantee better results for the treatment of aesthetic dysfunctions, such as localized fat and pathologies, such as lipomas.

Descriptors: Ozone; Adipocytes; Lipomas.

\section{Resumén}

El objetivo fue evaluar los efectos de la ozonoterapia en el tratamiento de la adiposidad. Se realizó una revisión integradora durante el mes de octubre de 2020, en las bases de datos SciELO, LILACS, PubMed y Academic Google, con los descriptores: oxigenoterapia, adiposidad y los correspondientes en portugués y español. Criterios de inclusión: artículos disponibles en su totalidad, en portugués, inglés y español y que contengan al menos dos descriptores en el título o resumen, publicados entre 2000 y 2020 . Se seleccionaron cinco artículos científicos, uno sobre obesidad, dos sobre lipomas y otros dos sobre submentonismo. grasa (papada). El ozono demostró ser un excelente agente lipolítico, reduciendo la adiposidad con pocas aplicaciones y sin efectos secundarios. Sin embargo, se necesitan más estudios sobre ozonoterapia y tratamiento de la adiposidad para establecer las concentraciones ideales y la frecuencia de aplicación del ozono con el fin de garantizar mejores resultados en el tratamiento de disfunciones estéticas, como la grasa localizada y patologías, como los lipomas.

Descriptores: Ozono; Asipocitos; Lipoma. 


\section{Introdução}

O acúmulo de gordura (adiposidade) está relacionado ao sobrepeso e obesidade. A obesidade é fator de risco para várias doenças, incluindo diabetes, câncer e problemas cardiovasculares ${ }^{1}$.

As adiposidades estão localizadas em diferentes regiões do corpo, como região submentoniana, região préaxilar, abdome, costas, flancos, quadris, braços, coxas e alteram negativamente a autoestima do paciente. Pequenas mudanças estéticas, como redução da gordura localizada, têm potencial para estabelecer melhor relação do indivíduo com a autoimagem e desta forma também melhorar a saúde mental².

O acúmulo de células de tecido adiposo (adipócitos) envolto por cápsula fibrosa e localizado no tecido subcutâneo, músculos, nervos, ossos, órgãos internos ou na cavidade abdominal compreende uma condição patológica denominado lipoma e não está associada à obesidade ${ }^{3}$. A etiologia do lipoma ainda é desconhecida e controversa ${ }^{4}$.

As adiposidades localizadas e, possivelmente, os lipomas estão associados ao estresse oxidativo, processos inflamatórios e excessiva liberação de espécies reativas de oxigênio $(\mathrm{ROS})^{5,6}$. Portanto, o organismo necessita de um sistema desintoxicante e antioxidante para combater o estresse oxidativo. O fator de transcrição $\mathrm{Nrf2}$, quando ativado corretamente, é capaz de restaurar a homeostase redox e melhorar a saúde humana ${ }^{7,8}$.

A ativação do Nrf2 por vários diferentes mecanismos (restrição calórica, ozonioterapia, oxigêniohiperbárico, exercício físico) podem ser maneiras de melhorar a saúde ${ }^{7}$. Assim, o uso da ozonioterapia como terapia alternativa e adjuvante precisa ser mais bem estudada no caso de patologias e disfunções estéticas que envolvam adiposidades.

Atualmente, a ozonioterapia (O2-O3) é considerada um método de tratamento minimamente invasivo, seguro e eficaz, com aplicações em diferentes concentrações e locais do corpo, na forma de gás, água e/ou óleo ${ }^{9}$ e muito útil para a redução de adiposidades localizadas.

Desde o descobrimento do ozônio pelo químico alemão Christian Friedrich Schönbein, em 1840, o uso médico tem aumentado em diferentes partes do mundo e tem havido maior interesse pelos profissionais de saúde em saber como funciona e quais são os seus benefícios ${ }^{10}$.

Relatos de seu uso constam já na Primeira Guerra Mundial, no qual eram poucos os recursos médicos e o ozônio era usado como alternativa para tratar feridas e gangrenas gasosas pós-traumáticas, por sua ação antibactericida, anti-inflamatória e funções hemodinâmicas e analgésicas ${ }^{11}$.

No Brasil, a ozonioterapia é considerada um tratamento complementar integrativo pela Portaria n.․ 702, de 21 de março de $2018^{12}$ e é oferecida pelo Sistema Único de Saúde (SUS).

Apesar do reconhecimento do Ministério da Saúde em relação à eficácia e segurança da ozonioterapia no tratamento de diversas patologias, essa prática integrativa não recebeu o aval do Conselho Federal de Medicina (CFM) no país. Contudo, o Conselho Federal de Enfermagem (COFEN) regulamentou a ozonioterapia como prática do enfermeiro no Brasil através do Parecer Normativo n. 01, de 20 de fevereiro de $2020^{13}$.

Dentre os efeitos terapêuticos do ozônio inclui ação antioxidante contra radicais livres ${ }^{14}$; aumento da flexibilidade dos eritrócitos, facilitando a passagem dos mesmos pelos vasos sanguíneos e garantindo maior suprimento de oxigênio tecidual devido ao aumento do 2,3difosfoglicerato (responsável pela transferência de 02 de hemoglobina aos tecidos); redução da agregação plaquetária; efeito analgésico; anti-inflamatório; bactericida, fungicida e viricida ${ }^{6,15-17}$.

O ozônio medicinal ainda tem ações no metabolismo, promovendo lipólise e quebra de ácidos graxos insaturados em compostos solúveis em água; participação no metabolismo de proteínas devido à sua afinidade com grupos sulfidrila, reagindo assim com aminoácidos essenciais, como metionina e triptofano ou com cisteína, contendo enxofre; aumento da glicólise, o que aumenta a disponibilidade de ATP nas células e, portanto, nos tecidos, especialmente os nervos ${ }^{15,18}$.

Sendo assim, o objetivo deste estudo foi verificar as evidências científicas existentes da ozonioterapia no tratamento da gordura localizada e lipomas e responder à pergunta norteadora: Quais os efeitos da ozonioterapia no tratamento de adiposidades?

\section{Metodologia}

Trata-se de uma revisão integrativa da literatura, na qual os trabalhos científicos utilizados na pesquisa foram levantados, via on-line, nas bases eletrônicas de dados Literatura Latino-Americana e do Caribe em Ciências da Saúde (LILACS), Scientific Eletronic Library Online (SciELO), PubMed e Google Acadêmico. O levantamento de publicações foi realizado utilizando-se os seguintes descritores, em inglês, oxygen-ozone therapy, adiposity e, os correspondentes em português e espanhol.

A pesquisa obedeceu aos critérios de inclusão a) artigos científicos; b) estar disponível em texto completo (do tipo original, de revisão, relato de experiência, estudo de caso, estudo descritivo observacional) de forma gratuita; c) que continham pelo menos dois descritores no título ou resumo; d) estudos que abordavam a temática específica; e) estudos disponíveis no idioma inglês, espanhol e português; f) recorte temporal de 2010 a 2020.

A escolha do ano inicial do recorte temporal devese ao aumento das publicações sobre as aplicações clínicas da ozonioterapia.

Foram excluídos os trabalhos que não atendiam à temática central; dissertações, teses e estudos em duplicatas em mais de uma base de dados.

Para coleta de dados e análise sistematizada das publicações foi utilizado um instrumento, que constou de dados de identificação da publicação (ano, título do artigo, autores); tipo de estudo e principais resultados.

A coleta de dados ocorreu no mês de outubro de 2020, de forma duplo cego independente. 
Figura 1. Fluxograma da presente revisão integrativa. Três Lagoas, MS, Brasil, 2020

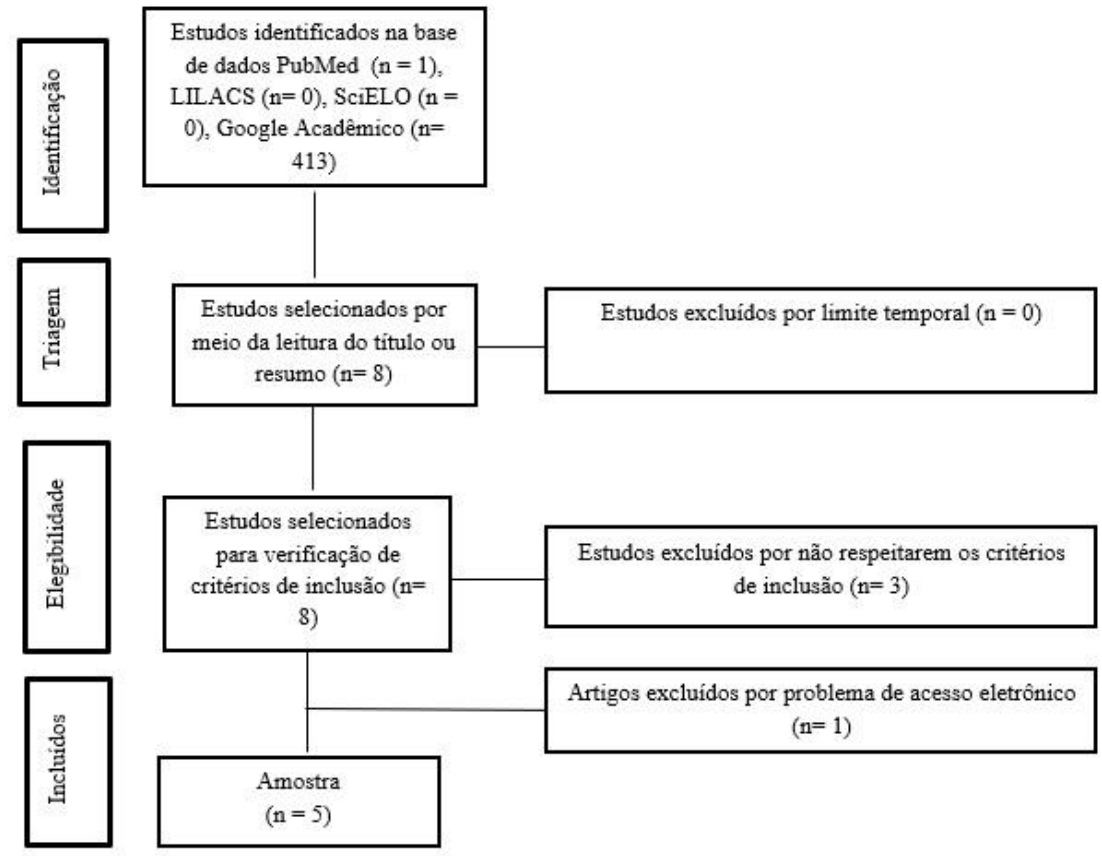

\section{Resultados e Discussão}

No período de dez anos (2010 a 2020) foram identificados 414 artigos nas bases de dados estudadas, porém, após análise e critérios de inclusão, foram selecionados 5 trabalhos no estudo (Figura 1), os quais estão listados no Quadro 1.

Quadro 1. Trabalhos selecionados na base de dados PubMed e Google Acadêmico referentes à ozonioterapia no tratamento de adiposidades. Três Lagoas, MS, Brasil, 2010-2020

\begin{tabular}{|c|c|c|c|c|c|c|}
\hline Ano & Autores & $\begin{array}{l}\text { Tipo de } \\
\text { Estudo }\end{array}$ & $\begin{array}{c}\text { Tipo de } \\
\text { patologia }\end{array}$ & Amostra & Tratamento & Resultados \\
\hline 2011 & $\begin{array}{l}\text { Ashem e } \\
\text { Nagib }^{19}\end{array}$ & Randomizado & $\begin{array}{l}\text { Obesidade } \\
\text { grau II }\end{array}$ & $\begin{array}{l}30 \text { pacientes, de } 25 \\
\text { a } 45 \text { anos, com } \\
\text { obesidade grau II } \\
\text { de ambos os sexos } \\
\text { e com Índice de } \\
\text { Massa Corpórea } \\
\text { (IMC) de } 30-40 . \\
\text { Foram distribuídos } \\
\text { aleatoriamente em } \\
\text { dois grupos: Grupo } \\
1: \text { quinze pacientes } \\
\text { receberam } \\
\text { ozonioterapia com } \\
\text { dieta hipocalórica. } \\
\text { Grupo 2: quinze } \\
\text { pacientes } \\
\text { receberam apenas } \\
\text { dieta hipocalórica }\end{array}$ & $\begin{array}{l}\text { Cada paciente do grupo } \\
1, \quad \text { recebeu } \\
\text { ozonioterapia em forma } \\
\text { de insuflações retais } \\
\text { com concentração de } \\
\text { ozônio de } 20 \mu \mathrm{g} / \mathrm{mL} \text {, } \\
\text { aumentada } \\
\text { gradualmente até } 40 \\
\mu \mathrm{g} / \mathrm{mL} \text {. O volume variou } \\
\text { de } 150-300 \text { mL. O } \\
\text { procedimento foi } \\
\text { realizado } 2 \text { vezes por } \\
\text { semana com duração de } \\
6 \text { meses }\end{array}$ & $\begin{array}{l}\text { Em ambos os grupos houve } \\
\text { diminuição significativa no IMC } \\
\text { e circunferência da cintura. } \\
\text { Porém, as maiores reduções } \\
\text { foram denotadas no grupo } \\
\text { ozônio com dieta hipocalórica, } \\
\text { sendo IMC de } 39,53 \text { para } 30,67 \\
\mathrm{Kg} / \mathrm{m}^{2} \text { e circunferência da } \\
\text { cintura de } 119,47 \text { para } 100,20 \\
\mathrm{~cm}\end{array}$ \\
\hline 2018 & $\begin{array}{l}\text { Cardoso et } \\
\text { al. }{ }^{18}\end{array}$ & Clínico & $\begin{array}{l}\text { Lipoma } \\
\text { doloroso }\end{array}$ & $\begin{array}{l}20 \text { pacientes, } \\
\text { sendo } 16 \text { mulheres } \\
\text { e } 4 \text { homens, de } 30 \\
\text { a } 80 \text { anos }\end{array}$ & $\begin{array}{l}\text { Foram aplicados } 10 \mathrm{~mL} \\
\text { por ponto } \\
\text { (concentração de } 4 \\
\mu g / \mathrm{mL} \text { ). } \\
\text { realizadas } 10 \text { aplicações } \\
\text { por paciente, duas } \\
\text { vezes por semana }\end{array}$ & $\begin{array}{l}\text { Redução de aproximadamente } \\
4 \mathrm{~cm} \text { do lipoma em cada } \\
\text { paciente. Todos tiveram uma } \\
\text { redução da pontuação na } \\
\text { escala visual analógica de dor } \\
\text { (de } 7 \text { para } 1 \text { ponto), além disso, } \\
\text { houve melhora da habilidade } \\
\text { motora em todos os pacientes }\end{array}$ \\
\hline 2019 & $\begin{array}{l}\text { Kara e } \\
\text { Kara }^{25}\end{array}$ & Cínico & $\begin{array}{l}\text { Lipoma } \\
\text { doloroso no } \\
\text { antebraço } \\
\text { direito e } \\
\text { lipomas não } \\
\text { dolorosos no } \\
\text { antebraço } \\
\text { esquerdo e } \\
\text { região } \\
\text { abdominal }\end{array}$ & $\begin{array}{l}\text { Mulher de } 31 \text { anos } \\
\text { com história } \\
\text { familiar de lipomas } \\
\text { múltiplos }\end{array}$ & $\begin{array}{l}\text { Aplicação local } 10 \mathrm{~g} \text { (10 } \\
\mathrm{mL}) \text { de ozônio no } \\
\text { lipoma do antebraço } \\
\text { direito. Após uma } \\
\text { semana, outra aplicação } \\
\text { de } 5 \mathrm{~g}(5 \mathrm{~mL}) \text { de } \mathrm{O}_{3}\end{array}$ & $\begin{array}{l}\text { Lipoma do antebraço direito } \\
\text { reduziu de } 3,05 \times 0,72 \mathrm{~cm} \text { (área } \\
\text { de secção transversal: } 1,63 \\
\mathrm{~cm}^{2} \text { ) para } 1,09 \text { por } 0,63 \mathrm{~cm} \\
(\text { área de secção transversal: } \\
0,61 \mathrm{~cm}^{2} \text { ) na primeira } \\
\text { aplicação. Além disso, a dor } \\
\text { diminui imediatamente após a } \\
\text { ozonioterapia }\end{array}$ \\
\hline
\end{tabular}




\begin{tabular}{|c|c|c|c|c|c|c|}
\hline 2019 & $\begin{array}{l}\text { Lopes, } \\
\text { Matrone, } \\
\text { Lopes }^{24}\end{array}$ & Clínico & $\begin{array}{l}\text { Gordura } \\
\text { submentonia } \\
\text { na (papada) }\end{array}$ & $\begin{array}{l}17 \text { mulheres, faixa } \\
\text { etária de } 20 \text { a } 55 \\
\text { anos }\end{array}$ & 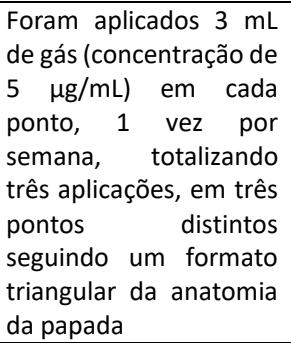 & $\begin{array}{l}\text { Redução significativa da } \\
\text { adipometria (de } 38,77 \text { para } \\
21,53 \mathrm{~mm} \text { ) e paquimetria (de } \\
97,41 \text { para } 71,93 \mathrm{~mm} \text { ) na } \\
\text { terceira semana quando } \\
\text { comparada ao início do } \\
\text { tratamento }\end{array}$ \\
\hline 2020 & Varão ${ }^{5}$ & $\begin{array}{l}\text { Revisão } \\
\text { bibliográfica }\end{array}$ & $\begin{array}{l}\text { Gordura } \\
\text { submentonia } \\
\text { na (papada) }\end{array}$ & $\begin{array}{l}\text { Não citou o } \\
\text { número de artigos } \\
\text { encontrados na } \\
\text { revisão } \\
\text { bibliográfica }\end{array}$ & $\begin{array}{l}1 \text { a } 8 \mu \mathrm{g} / \mathrm{mL} \text { de } \mathrm{O}_{3} \text { em } 12 \\
\text { aplicações locais, sendo } \\
\text { duas vezes por semana } \\
\text { e } 250 \mathrm{~mL} \text { de solução } \\
\text { salina } 0,9 \% \text { com } 3 \text { a } 5 \\
\mu \mathrm{g} / \mathrm{mL} \text { de } \mathrm{O}_{3} \text { duas vezes } \\
\text { por semana, totalizando } \\
6 \text { aplicações sistêmicas }\end{array}$ & $\begin{array}{l}\text { O trabalho de revisão } \\
\text { bibliográfica demonstrou que a } \\
\text { ozonioterapia é melhor do que } \\
\text { lipoaspiração ou outros } \\
\text { procedimentos estéticos na } \\
\text { redução da adiposidade da } \\
\text { papada, com menos efeitos } \\
\text { colaterais e combate ao } \\
\text { estresse oxidativo e } \\
\text { inflamatório da adiposidade }\end{array}$ \\
\hline
\end{tabular}

Um bom programa de emagrecimento com redução de peso corporal, índice de massa corpórea (IMC) e circunferência abdominal deve associar dieta hipocalórica, exercícios físicos e tratamentos estéticos. Em geral, um déficit calórico de cerca de $7.700 \mathrm{kcal}$ leva a perda de cerca de um quilograma de gordura ${ }^{19}$.

Sabe-se que uma dieta hipocalórica proporciona uma perda de $1,5 \mathrm{Kg}$ em uma semana, com redução significativa dos níveis pressóricos, diminuição de 20 a $25 \%$ do colesterol sérico e redução considerável dos níveis de glicose em diabéticos ${ }^{20}$.

No estudo de Ashem e Nagib ${ }^{19}$, quinze pacientes submetidos à dieta hipocalórica e ozonioterapia na forma de insuflação retal apresentaram redução significativa do IMC (de 39,53 para $30,67 \mathrm{Kg} / \mathrm{m}^{2}$ ) e da circunferência da cintura (de 119,47 para 100,20 cm). Os autores justificaram que o ozônio promoveu lipólise, diminuição da resistência à insulina, acelerou a glicólise e aumentou os parâmetros de ativação metabólica.

Em relação ao emagrecimento e diminuição da gordura localizada deve-se, também, considerar outros fatores, como a prática regular de atividades físicas e a manutenção de alimentação equilibrada e saudável ${ }^{21}$.

É fundamental ressaltar que uma das causas do excesso de consumo de comida é o uso generalizado de antibióticos orais. Os antibióticos destroem as bactérias alvos, porém, também matam aqueles da flora intestinal, que é necessária para uma digestão saudável. Como resultado, a sensação de fome vem com mais frequência e dura mais tempo. Assim, o corpo tenta compensar a digestão ineficaz, aumentando a quantidade de comida ingerida e, portanto, conduzindo ao sobrepeso e obesidade ${ }^{15}$.

Quando a flora fisiológica está equilibrada e em simbiose com o organismo torna-se benéfica para ambos, e é referido como eubiose. Quando, por razões diversas, existe alteração funcional da mucosa do colón e modificação da flora bacteriana que reside no intestino, temos a disbiose ${ }^{22}$.

Os principais sintomas da disbiose são: má digestão, inchaço, constipação alternando com disenteria fecal, mudanças de humor, distúrbios do sono, candidíase vaginal, dismenorreia, astenia, halitose, dores de cabeça e alergias ${ }^{23}$.
Uma pesquisa com 34 pacientes com disbiose intestinal que receberam três copos de água ozonizada de $125 \mathrm{ml}$ e três insuflações retais de ozônio (concentração $40 \mu \mathrm{g} / \mathrm{mL}$ ), totalizando $250 \mathrm{ml}$ por sessão, três vezes por semana, durante 45 dias, apresentaram diminuição significativa da halitose, gastralgia, astenia, distensão abdominal e episódios de diarreia ${ }^{15}$.

A adiposidade localizada pode ser evitada na maioria dos casos com uma dieta adequada e estilo de vida saudável, porém o estudo de Ashem e Nagib $^{19}$ apontou a ozonioterapia como tratamento adjuvante no emagrecimento e redução da gordura localizada.

Dois estudos demonstraram os efeitos da ozonioterapia no tratamento de adiposidade submentoniana ${ }^{5,24}$. O acúmulo de gordura na região submentoniana representa uma desvantagem estética significativa, causando o queixo duplo e também implica em sério problema de saúde, pois está associado à apnéia do sono, estresse oxidativo e até morte por hipóxia cerebral e insuficiência respiratória ${ }^{5,24}$.

Muitos estudos clínicos são necessários para estabelecer protocolo de tratamento que seja eficaz para a redução volumétrica do tecido adiposo com ozonioterapia na região submentoniana, pois, a concentração de ozônio, via de administração e frequência de aplicação diverge na literatura estudada. Varão descreveu aplicações locais e sistêmicas de ozônio, as primeiras na concentração de 1 a 8 $\mu \mathrm{g} / \mathrm{mL}$ duas vezes por semana, totalizando 12 aplicações e as sistêmicas, sendo $250 \mathrm{~mL}$ de solução salina $0,9 \%$ com 3 a $5 \mu \mathrm{g} / \mathrm{mL}$ de $\mathrm{O}_{3}$ duas vezes por semana, totalizando 6 aplicações ${ }^{24}$.

Embora faltem estudos randomizados sobre ozonioterapia no tratamento de lipomas, uma pesquisa com 20 pacientes que tinham lipomas dolorosos demonstrou que as injeções de oxigênio-ozônio reduziram em média 4 centímetros o tamanho dos lipomas e a intensidade da dor (pontuação média da escala visual analógica diminuiu de 7 para 1) em 10 sessões $^{18}$.

Outro estudo apontou a redução de um terço do tamanho do lipoma doloroso de antebraço direito de uma paciente de 31 anos, que possuía outros lipomas no antebraço esquerdo e região abdominal. A área de secção 
transversal do lipoma reduziu de $1,63 \mathrm{~cm}^{2}$ para $0,61 \mathrm{~cm}^{2} \mathrm{com}$ apenas uma aplicação de $10 \mathrm{~g}(10 \mathrm{~mL})$ de ozônio ${ }^{25}$.

Portanto, não há dúvidas que o ozônio atue de forma eficiente como um agente lipolítico porque esse gás se dissolve na água intersticial e os lipídios são os seus substratos preferenciais, sendo quebrados em lipoperóxidos, hidroperóxidos e produtos de oxidação lipídica de pequeno peso molecular ${ }^{26}$.

A ozonioterapia é cientificamente aprovada e é um tratamento altamente eficaz para lipodistrofia ${ }^{6}$. Esta eficácia é alcançada porque o oxigênio-ozônio exerce sua ação por meio de três mecanismos principais: i) quebra de ácidos graxos longos em cadeias curtas e, portanto, hidrofílicas; facilitando o transporte desses pelos fluidos corporais e, permitindo, sua eliminação pelo organismo; (ii) facilita a remoção de líquidos intersticiais estagnados (edema); (iii) o oxigênio-ozônio se liga à membrana dos glóbulos vermelhos, entregando mais oxigênio aos tecidos e, portanto, ativando o metabolismo local e melhorando a circulação venosa e linfática ${ }^{18}$.

Paradoxalmente, o ozônio em baixas concentrações (5 a $10 \mu \mathrm{g} \mathrm{O}_{3} / \mathrm{mL}$ ) em células-tronco adultas derivadas do estroma do tecido adiposo (hADAS) in vitro induziu adipogênese, mesmo na ausência de fatores adipocitários ${ }^{27}$.

As células hADAS têm capacidade de se diferenciar in vitro em linhagens de células meso, ecto e endodérmicas e podem ser reprogramadas como células-tronco pluripotentes com mais eficiência do que outros tipos de células. As referidas células são, portanto, consideradas uma ferramenta poderosa na medicina regenerativa $\mathrm{e}$ engenharia de tecidos ${ }^{28}$. No entanto, concentrações maiores de ozônio $(20 \mu \mathrm{g} / \mathrm{mL})$ mostrou causar destruição das células tronco por aumento do estresse oxidativo ${ }^{27}$.

Portanto, existem evidências significativas da utilização da ozonioterapia como terapia adjuvante no tratamento de lipomas e adiposidades localizadas. Para o enfermeiro é necessário que tenha competência técnica na administração deste gás e como se trata de um novo campo crescente como técnica terapêutica, os profissionais da Enfermagem serão confrontados diariamente com os avanços científicos da ozonioterapia, cabendo aos mesmos estudos aprofundados e aperfeiçoamentos constantes.

\section{Conclusão}

A alimentação adequada e prática regular de exercícios físicos aumenta a chance de resultados positivos em relação à ozonioterapia para o tratamento de adiposidades localizadas. No caso dos lipomas, a ozonioterapia diminuiu a dor e reduziu o tamanho com poucas aplicações.

Nesse sentido, a ozonioterapia mostrou-se eficaz no tratamento de gordura localizada e lipomas. Porém, são necessários mais estudos clínicos com grandes amostras para o estabelecimento de protocolos, sobretudo, com concentrações e frequência de aplicação do ozônio bem como acompanhamento dos pacientes por mais tempo para verificar a eficácia do tratamento em longo prazo.

\section{Referências}

1. Mariath $\mathrm{AB}$, et al. Obesidade e fatores de risco para o desenvolvimento de doenças crônicas não transmissíveis entre usuários de unidade de alimentação e nutrição. Cad Saúde Pública. 2007; 23(4): 897-905. https://doi.org/10.1590/S0102-311X2007000400017

2. Soaigher KA, Acencio FR, Cortez DAG. O poder da vaidade e do autocuidado na qualidade de vida. Cinergis. 2016; 18(1): 1-4. https://doi.org/10.17058/cinergis.v18i1.8218

3. Lenza M, Lenza MV, Carrerra EF, Ferretti M. Lipoma subdeltoídeo como causa de síndrome do impacto no ombro - um relato de caso. Einstein. 2014; 12(3): 351-354. https://doi.org/10.1590/S1679-45082014RC2934

4. Moraes FB, et al. Lipoma intraósseo do ilíaco: relato de caso. Rev Bras Ortop. 2016; 51(1): 113-117. https://doi.org/10.1016/j.rboe.2015.12.011

5. Varão J. Tratamiento de lipólisis de grasa submentoniana con ozonoterapia y sus efectos en el síndrome de apnea obstructiva crónica y estética. Ozone Ther Global J [Internet]. 2020 [acesso em 05 jan 2021]; 10(1): 207-239. Disponível em:

http://www.revistaespañoladeozonoterapia.es/index.php/reo/article/view/214

6. Cuccio G, Franzini M. Oxygen-ozone therapy in the treatment of tissue adipose diseases. Ozone Therapy. 2016; 1(2): 25-33. https://doi.org/10.4081/ozone.2016.6270

7. Bocci V, Valacchi G. Nrf2 activation as target to implement therapeutic treatments. Frontiers in Chemistry. 2015; 3(4): 1-6. DOI: 10.3389/fchem.2015.00004

8. Silva DC, Cerchiaro G, Honorio KM. Relações patofisiológicas entre estresse oxidativo e arteriosclerose. Química Nova [Internet]. 2011 [acesso em 05 jan 2021]; 34(2): 300-305. Disponível em: http://quimicanova.sbq.org.br/detalhe_artigo.asp?id=4482

9. Saini R. Ozone therapy in dentistry: A strategic review. J Nat Sci Biol Med. 2011; 2(2): 151-153.

10. Associação Espanhola de Profissionais Médicos de Ozonoterapia (AEPROMO). Declaração de Madrid sobre ozonioterapia [Internet]. 2010 [acesso em 15 nov 2020]. Disponível em: http://www.spozonoterapia.com/pdf/portuguese_declaration.pdf

11. Elvis AM, Ekta JS. Ozone therapy: A clinical review. J Nat Sci Biol Med. 2011; 2(1): 66 -70. https://dx.doi.org/10.4103\%2F0976-9668.82319

12. Ministério da Saúde (BR). Portaria n. ${ }^{\circ} 702$, de 21 de março de 2018 . Altera a Portaria de consolidação no $2 / G M / M S$, de 28 de setembro de 2017, para incluir novas práticas na Política Nacional de Práticas Integrativas e Complementares - PNPIC [Internet]. Brasília (DF): MS; 2018.

13. Conselho Federal de Enfermagem (COFEN). Parecer Normativo $n .^{\circ} 01$, de 20 de fevereiro de 2020. Regulamentar a ozonioterapia como prática do enfermeiro no Brasil [Internet]. Brasília (DF): COFEN; 2020.

14. Valdenassi L, Franzini M, Simonetti V, Ricevuti G. Oxygen-ozone therapy: paradoxical stimulation of ozone. Ozone Therapy. 2016; $1(1): 2$ 4. https://doi.org/10.4081/ozone.2016.5837 
15. Loprete F, Vaiano F. The use of ozonated water and rectal insufflation in patients with intestinal dysbiosis. Ozone Therapy 2017; 2(3): 5661. https://doi.org/10.4081/ozone.2017.7304

16. Franzini $\mathrm{M}$, et al. Oxygen-ozone $\left(\mathrm{O}_{2}-\mathrm{O}_{3}\right)$ immunoceutical therapy for patients with COVID-19. Preliminary evidence reported. Int Immunopharmacol. 2020; 88: 106879. https://dx.doi.org/10.1016\%2Fj.intimp.2020.106879

17. Bialoszewski $D$ et al. Activity of ozonated water and ozone against Staphylococcus aureus and Pseudomonas aeruginosa biofilms. Med Sci Monit. 2011; 17(11): 339-344. DOI: 10.12659/msm.882044

18. Cardoso O, Rossi P, Galoforo A, Collodo G. Ozone therapy in painful lipodystrophies. A preliminary study. Ozone Therapy. $2018 ; 3(1): 9-12$. https://doi.org/10.4081/ozone.2018.7510

19. Ashem HN, Nagib SH. Ozone therapy as an adjunctive modality for weight reduction in grade II adult obese subjects. Bull Fac Ph Th Cairo Univ. 2011; 16(2): 71-77.

20. American Diabetes Association. Eating with type 2 diabetes. Clinical Diabetes; 2007: 25(3): 104.

21. Bocci V. Ozone A New Medical Drug, Kluwer Academic. Publisher. 2005; (2): 1-285. https://doi.org/10.1007/978-90-481-9234-2

22. Reid G, Sanders ME, Gaskins HR, et al. New scientific paradigms for probiotics and prebiotics. J Clin Gastroenterol. 2003; 37: 105-18. DOI: 10.1097/00004836-200308000-00004

23. Mearin F, Rey E, Balboa A. Motility and functional gastrointestinal disorders. Gastroenterol Hepatol. 2014; 37(3): 3-13. DOI: 10.1016/S0210-5705(14)70078-0

24. Lopes S, Matrone M, Lopes I. Protocolo para lipólise submentoniana empregando ozonioterapia. Tox Update. 2019; 2(7): 6-14.

25. Kara O, Kara M. Lipolysis of a painful lipoma with ozone: the role of ultrasound in the diagnosis and quantification of the treatment. Med Gas Res. 2019; 9(3): 168-169. https://dx.doi.org/10.4103\%2F2045-9912.267000

26. Bocci V. The clinical application of ozonetherapy. In: Ozone. Dordrecht: Springer; 2010.

27. Costanzo M, et al. Low ozone concentrations promote adipogenesis in human adipose-derived adult stem cells. Eur J Histochem. 2018; 62 (3): 253-256. https://dx.doi.org/10.4081\%2Fejh.2018.2969

28. Ong WK, Sugii S. Adipose-derived stem cells: fatty potentials for therapy. Int J Biochem Cell Biol. 2013; 45: 1083-1086. DOI: 10.1016/j.biocel.2013.02.013 